\title{
Ontología y deontología en los medios de comunicación social
}

Recibido: 23 de noviembre de 2011

Aceptado: 16 de mayo de 2012

Publicado: 31 de octubre de 2012
Ramón Abarca Fernández

rabarcaf@ucsm.edu.pe

Universidad Católica de Santa María (Arequipa, Perú)

Resumen: Esta investigación cualitativa analiza el decreto conciliar Inter Mirifica (1963) que establece la responsabilidad de los medios de comunicación social frente a la cultura, la ciencia, la multiculturalidad, así como frente a las tecnologías de la información, Internet, el ciberperiodismo y la perspectiva histórico-ecológica de la comunicación. Se concluye que Inter Mirifica expresa la razón de ser de los medios de comunicación social y exige que sean empleados con rectitud, prudencia y sensatez.

Palabras clave: Comunicación, descubrimientos comunicacionales, medios de comunicación social, infomulticulturalidad, periodismo digital, multimedia.

Abstract: This qualitative research analyzes Decree Inter Mirifica (1963), which states the responsibility of Mass Media and its relation to Culture, Science, Multiculturalism, as well as the technologies of the information, Internet, Digital Journalism and historicalecological Communication Perspective, concluding that Inter Mirifica expresses the essence of Media: its use requires righteousness, prudence and wisdom.

Key words: Communication, Discovery Communications, Mass Media, Info-Multiculturalism, Digital Journalism, Multimedia.

\section{Visión conceptual-terminológica de la comunicación}

La historia del ser humano está marcada por la necesidad de comunicarse e interactuar con otros. Según Berelson "la comunicación es la transmisión de información, ideas, 
emociones y habilidades a través de símbolos, palabras, imágenes, figuras, sonidos" (ápud De León, 2009). Este intercambio se enmarca en el tiempo, mediante la sociabilización que posibilita trazar metas y fines de los agrupamientos y cuyo proceso comunicativo es la base del desarrollo y de la personalización de todos los seres humanos ${ }^{1}$.

La comunicación conforma un factor constitutivo de la humanidad. Su fundamento más constante es persuadir o inducir a alguien a creer o llevar a cabo una acción. Asimismo, es un fenómeno inherente a la relación grupal, por medio del cual los individuos obtienen información acerca de otros y de su entorno.

La creación, búsqueda y obtención de información son acciones esenciales a la naturaleza humana. Tal vez por eso los grandes saltos evolutivos de la humanidad tienen como hito la instauración de algún nuevo instrumento de comunicación.

Según Habermas (ápud Pineda de Alcázar, 2011), los hablantes están dotados de competencia lingüística para hablar con sus semejantes: comunicar implica lo que se dice y aceptarlo. Así, el lenguaje permite el conocimiento y la comprensión, convirtiéndose en el eje de la consciencia transformadora, de la innovación social.

Lewin la conceptúa como un complejo sistema de acciones e interacciones grupales, donde una persona transmite un mensaje a otra y esta, a su vez, responde; lo cual genera un proceso circular y continuo. Bortot la concibe como un fenómeno que establece una relación entre dos o más personas, basada en el intercambio de mensajes y/o ideas, a través del cual se desarrollan todas las relaciones humanas (ápud Quinto, 2010). Para Martinet, es la utilización de un código para transmitir un mensaje, de una determinada experiencia, en unidades semiológicas, con el objeto de permitir, a los hombres, relacionarse entre sí (ápud Hernández y Mujica, 2008).

La comunicación se ha estructurado como ciencia gracias a las diferentes líneas de investigación que analizan los medios de comunicación social. En la actualidad, los métodos de investigación cualitativa permiten la exploración de la experiencia interna, el lenguaje, los significados culturales o las formas de interacción social relacionadas con la comunicación. La fuerza particular de la investigación cualitativa es su habilidad para centrarse en la práctica real in situ, observando cómo las interacciones son realizadas rutinariamente.

1 El pensamiento de Bernard Berelson (1912-1979) ha girado en torno al conocimiento de las relaciones entre medios de comunicación y política, pero también mostró su interés por el desarrollo específico de las ciencias de la comunicación y la experimentación metodológica en este ámbito. En sus últimos años de trabajo, sus planteamientos estuvieron cercanos a la corriente de los difusionistas de la innovación a través de los medios. 


\section{Decreto Inter Mirifica ${ }^{2}$}

Abordar el tema de los medios de comunicación social nos lleva, necesariamente, al 25 de enero de 1959, festividad de la conversión del Apóstol Pablo, cuando el Papa Juan XXIII anunció la realización del Concilio Ecuménico Vaticano II. Su cometido fue la reflexión profunda y pastoral sobre la doctrina de salvación recibida de los Apóstoles y su actualización según lo demandaban las circunstancias sociales e históricas del momento. En este contex to surgió el decreto Inter Mirifica sobre los medios de comunicación social, promulgado el 4 de diciembre de $1963^{3}$.

El documento ${ }^{4}$ está integrado por los apartados que repasaremos a continuación:

\subsection{Proemio: "Maravillosos inventos de la técnica"}

En el numeral 1 se manifiesta que "la Madre Iglesia acoge y fomenta aquellos que miran principalmente al espíritu humano y han abierto nuevos caminos para comunicar facilísimamente las noticias, ideas y órdenes". El numeral 2 expresa que "estos instrumentos, rectamente utilizados, prestan ayuda valiosa al género humano, puesto que contribuyen eficazmente a distender y cultivar los espíritus y a propagar y afirmar el reino de Dios; sabe también que los hombres pueden utilizar tales medios contra los mandamientos del Creador y convertirlos en instrumentos de su propio daño".

En el segundo párrafo de este numeral se dice que el Concilio "considera su deber ocuparse de las principales cuestiones pertinentes a los medios de comunicación social. Confía, además, que su doctrina y disciplina, así presentadas, aprovecharán no sólo al bien de los cristianos, sino al progreso de todo el género humano". Ello significa que no podemos pasar por alto la importancia que tienen los medios y la responsabilidad con la cual debemos emplearlos.

\subsection{Capítulo I: "Normas reguladoras del recto uso de los medios de comunicación social”}

En el numeral 3 "se considera parte de su misión servirse de los instrumentos de comunicación social para predicar a los hombres el mensaje de salvación y enseñarles el recto uso de estos medios". Asimismo, en el numeral 4, se establece que "para el recto uso de estos medios es absolutamente necesario que todos los que se sirven de ellos conozcan

2 De acuerdo con el autor de este artículo, el Inter Mirifica empleó por vez primera la expresión "medios de comunicación social", que luego se popularizaría y difundiría por todo el mundo, especialmente en las universidades.

3 Este documento tiene como antecedentes principales dos encíclicas: Vigilanti Cura (1936) y Miranda Prorsus (1957), elaborados por los pontífices Pío XI y Pío XII respectivamente. Posteriormente, la instrucción pastoral Communio et progressio (1971), preparada por mandato del Concilio Vaticano II y la Aetatis Novae (1992) abordaron aspectos fundamentales relacionados con los medios de comunicación social.

4 Las siguientes citas y extractos provienen del texto alojado en la página electrónica de los Misioneros del Sagrado Corazón en el Perú (ver "fuentes consultadas"). 
y lleven a la práctica, en este campo, las normas del orden moral. Consideren, pues, la especial naturaleza de las cosas que se difunden a través de estos instrumentos, según la peculiar naturaleza de cada uno; tengan, a la vez, en cuenta, las circunstancias o condiciones todas, es decir, el fin, las personas, el lugar, el tiempo y demás datos que entran en juego en los diversos medios de comunicación, y aquellas otras circunstancias que pueden hacer perder su honestidad o cambiarla".

En el anexo "Recta conciencia en el uso de los medios de comunicación social" (numeral 5) se reitera que "en la utilización de estos medios de comunicación se formen recta conciencia sobre tal uso, en particular, por lo que se refiere a algunas cuestiones agriamente debatidas en nuestros días" y que "es evidente que tal información, por razón del moderno progreso de la sociedad humana y por los más estrechos vínculos entre sus miembros, resulta muy útil y, las más de las veces, necesaria, pues el intercambio público y puntual de noticias sobre acontecimientos y cosas facilita a los hombres un conocimiento más amplio y continuo de la actualidad, de modo que puedan contribuir eficazmente al bien común y al mayor progreso de toda la sociedad humana". Se requiere, pues un "intercambio público y puntual de las noticias", basado en la veracidad.

En el apartado "Primacía del orden moral" (numeral 6) se recuerda que "las controversias que surgen sobre este tema tienen su origen en falsas doctrinas sobre ética y estética, el Concilio proclama que la primacía del orden moral objetivo ha de ser aceptada por todos, puesto que es el único que supera y congruentemente ordena todos los demás órdenes humanos por dignos que sean, sin excluir el arte". En el numeral 7 se indica que "la narración, descripción y representación del mal moral, puede, sin duda, con el auxilio de los medios de comunicación social, servir para conocer y descubrir mejor al hombre y para hacer que mejor resplandezca y se exalte la verdad y el bien mediante oportunos y logrados efectos dramáticos; sin embargo, para que no produzcan mayor daño que utilidad a las almas, han de someterse plenamente a las leyes morales".

En el ítem "Deberes de justicia y caridad" (numeral 8) se manifiesta que "como quiera que la opinión pública ejerce hoy un poderoso influjo en todos los órdenes de la vida social, pública y privada, es necesario que todos los miembros de la sociedad cumplan sus deberes de justicia y caridad también en esta materia, y, por tanto, que con el auxilio de estos medios, se procure formar y divulgar una recta opinión pública". Consecuentemente, se debe actuar con rectitud y ponderación.

En el rubro "De los destinatarios de la información” (numeral 9) estipula que los “peculiares deberes competen a todos los destinatarios de la información, lectores, espectadores y oyentes que por su personal y libre elección reciben las informaciones difundidas por estos medios de comunicación. Pues, una recta elección exige que aquéllos fomenten todo lo que contribuye a la virtud, la ciencia y el arte, y eviten, en cambio, todo lo que pueda ser causa u ocasión de daño espiritual para ellos o para otros, por el mal ejemplo que puedan ocasionarles, y lo que favorezca las malas producciones y se oponga a las buenas”.

En el numeral 10 se estimula a que "los destinatarios, sobre todo los jóvenes, procuren acostumbrarse a ser moderados y disciplinados en el uso de estos instrumentos; pongan, además, empeño en entender bien lo oído, visto, leído; dialoguen con educadores y peritos 
en materia y aprendan a formar recto juicio. Recuerden los padres que es deber suyo vigilar cuidadosamente para que los espectáculos, las lecturas y cosas parecidas que puedan ofender la fe o las buenas costumbres no entren en el hogar y para que sus hijos no los vean en otra parte".

En el subtítulo "De los sujetos activos de la información” (numeral 11) se señala que "muy principal deber moral incumbe, en cuanto al recto uso de los medios de comunicación social, a los periodistas, escritores, actores, productores, realizadores, exhibidores, distribuidores, directores y vendedores, críticos y demás que de algún modo intervienen en la realización y difusión de las comunicaciones", recordando que "la mayor parte de los lectores y espectadores está compuesta de jóvenes, necesitados de prensa y espectáculos que les ofrezcan ejemplos de moralidad y los estimulen hacia sentimientos elevados".

En el numeral 12 se estipula que "las autoridades civiles tienen peculiares deberes en esta materia en razón del bien común al que se ordenan estos instrumentos. Por virtud de su autoridad y en función de la misma, les corresponde defender y tutelar una verdadera y justa libertad de información que la sociedad moderna necesita enteramente para su provecho, sobre todo en lo que atañe a la prensa. Defender la religión, fomentar la cultura, las bellas artes, proteger a los destinatarios para que puedan gozar libremente de sus legítimos derechos".

\subsection{Capítulo II: "Los medios de comunicación social y la acción pastoral de la Iglesia"}

En el numeral 13 se determina lo siguiente: "Procuren, de común acuerdo, todos los hijos de la Iglesia que los instrumentos de comunicación social se utilicen, sin la menor dilación y con el máximo empeño, en las más variadas formas de apostolado, tal como lo exigen las realidades y las circunstancias de nuestro tiempo, adelantándose, así, a las malas iniciativas, especialmente en aquellas regiones en las que el progreso moral y religioso reclama una mayor atención"; recordando que "los laicos que hacen uso de dichos instrumentos, procuren dar testimonio de Cristo, realizando, en primer término, sus propias tareas con pericia y espíritu apostólico y aportando, además, en lo que esté de su parte, mediante las posibilidades de la técnica, de la economía, de la cultura y del arte, su apoyo directo a la acción pastoral de la Iglesia”.

En el subtítulo "Medios de comunicación social católicos" (numeral 14) se acentúa que "han de fomentarse, ante todo, las publicaciones honestas. Ahora bien, para imbuir plenamente de espíritu cristiano a los lectores debe crearse y difundirse una prensa genuinamente católica -bien sea por parte de la propia jerarquía eclesiástica, o promovida por hombres católicos y dependiente de ellos- editada con la intención de formar, afirmar y promover una opinión pública en consonancia con el derecho natural y con las doctrinas y preceptos católicos, al mismo tiempo que divulga y desarrolla adecuadamente los acontecimientos relacionados con la vida de la Iglesia", promoviendo "la producción y exhibición de cintas destinadas al honesto descanso del espíritu, provechosas para la cultura y el arte humano, sobre todo aquellas que se destinan a la juventud, sean promovidas por todos los medios eficaces y aseguradas a toda costa; lo cual se logra, sobre todo, apoyando y coordinando las realizaciones y las iniciativas honestas, tanto de producción como de distribución, 
recomendando las películas que merecen elogio por el juicio concorde y por los premios de los críticos, fomentando y asociando entre sí las salas pertenecientes a empresarios católicos y a hombres honrados".

En el rubro "Formación católica para el uso de estos medios" (numeral 15) se menciona que "han de formarse oportunamente sacerdotes, religiosos y también laicos, que posean la debida competencia de estos instrumentos y puedan dirigirlos a los fines del apostolado"; y en el numeral 16 se expresa: "Habida cuenta de que el uso de los instrumentos de comunicación social, que se dirigen a personas diversas por edad y cultura, requieren en estas personas una formación y una experiencia acomodadas y apropiadas, deben favorecerse, multiplicarse y encauzarse, según los principios de las costumbres cristianas, las iniciativas que sean aptas para conseguir este fin".

En "Apoyo económico a los medios católicos de comunicación social” (numeral 17) se anota lo siguiente: "Siendo incompatible para los hijos de la Iglesia soportar insensiblemente que la doctrina de la salvación sea obstaculizada e impedida por razones técnicas o por los gastos, ciertamente cuantiosos, que son propios de estos medios, este Santo Concilio amonesta sobre la obligación de sostener y auxiliar los diarios católicos, las revistas e iniciativas cinematográficas, las emisoras y transmisiones radiofónicas y televisadas, cuyo principal fin es divulgar y defender la verdad y proveer a la formación cristiana de la sociedad humana. Igualmente, invita insistentemente a las asociaciones y a los particulares, que gozan de autoridad en las cuestiones económicas y técnicas, a sostener con largueza y de buen grado, con sus bienes económicos y su competencia, estos instrumentos".

En el numeral 18 se puntualiza: "Para que se vigorice el apostolado de la Iglesia en relación con los medios de comunicación social, debe celebrarse cada año en todas las diócesis del orbe, a juicio del Obispo, un día en el que los fieles sean adoctrinados sobre sus obligaciones en esta materia, invitados a orar por esta causa y a entregar una limosna para este fin, que será empleada para sostener y fomentar, según las necesidades del orbe católico, las instituciones e iniciativas promovidas por la Iglesia en este sector".

En el subtítulo "Organismos adecuados" (numeral 19) se señala que "para ejercitar la suprema cura pastoral sobre los instrumentos de comunicación social, el Sumo Pontífice tiene a su disposición un peculiar organismo de la Santa Sede". En el numeral 20 se expresa que "será competencia de los Obispos, en sus propias diócesis, vigilar estas obras e iniciativas, promoverlas y, en cuanto atañen al apostolado público, ordenarlas, sin excluir aquellas que están sometidas a la dirección de los religiosos exentos". En el numeral 21 se indica que "la misión de estas oficinas será velar para que la conciencia de los fieles se forme rectamente sobre el uso de estos instrumentos y para estimular y organizar todo lo que los católicos realizan en este campo".

En el ítem "Trabajo coordinado" (numeral 22) se establece lo siguiente: "Puesto que la eficacia de tales instrumentos traspasa los límites de las naciones, y es como si convirtiera a cada hombre en ciudadano de la Humanidad, coordínense las iniciativas de este género, lo mismo en el plano nacional que en el internacional"s.

5 El documento se adelanta al paradigma de la "Aldea global" de McLuhan e igualmente a Kovadloff (2008) cuando afirma: "El enorme desafío que plantea el siglo XXI es entender que el hombre está convocado a ser un ciudadano planetario, llámese ciudadano de la aldea, llámese ciudadano de la villa, ya no es ni siquiera el ciudadano del pueblo, ya no es siquiera el ciudadano de la nación; es el ciudadano planetario. Pero, entonces, ¿acaso la nación no importa? No. Vengamos desde el ideal planetario hacia el ideal nacional. Esto es, venir del futuro hacia el presente". 


\section{Surgimiento de la multiculturalidad}

La revolución de las telecomunicaciones y de la transmisión de datos ha empujado al mundo hacia la formación de una "aldea global" que cobija una serie de conflictos y problemáticas ( $c f$. Almiron, 2003). En ese sentido, la diversidad es uno de los rasgos de la posmodernidad. El fenómeno social conocido como "multiculturalismo" es un término no exento de ambigüedades y que requiere de ciertas precisiones.

Multiplicidad o variedad de culturas ha habido siempre. Lo que hoy aparece, como novedoso, es la convivencia de diversas culturas en un marco político común, lo cual se opone al "aislacionismo" (González, 2005). Del mismo modo, se habla de "pluralismo": un paradigma que se afirma superando la unicidad, el universalismo y el absolutismo del pensamiento tradicional. Se trata de aprehender la complejidad de la realidad más profunda de la vida en todos sus aspectos, incluidos los sociales, culturales y religiosos.

La complejidad de la realidad, en su condición plural, provoca y exige discernimiento. Requiere un nuevo despertar a partir de la alteridad y de la pluralidad, dejándose de lado la subjetividad y la identidad con pretensiones de universalidad exclusiva y de unicidad absoluta. Exige, asimismo, reconocer con valentía el cambio epistemológico lleno de consecuencias prácticas, de nuevas posturas que se están produciendo, de forma irrevocable, en nuestros días ( $c f$. Torres, Susin y Sobrino, 2007).

La multiculturalidad promueve el reconocimiento de la diferencia cultural así como el derecho a ella, configurándose como una propuesta de organización social, como un modelo de política pública y como una filosofía social de reacción que tiende a uniformar la cultura en tiempos de globalización ${ }^{6}$. Patzig afirma que "como miembros de una comunidad de hombres, dependemos de la colaboración y el consenso de los otros" (ápud Habermas, 2000). Entonces, si la multiculturalidad es un hecho, o mejor, un proceso, la integración cultural es una necesidad, puesto que radica y se enraízan en la dignidad y valores naturales de la persona. Por tanto, los valores fundamentales son lo necesariamente común, más allá de lo legítimamente diferente.

En un mundo globalizado y caracterizado por tener una gran diversidad cultural, es común pensar que unas culturas influyen sobre otras, gracias al intercambio de información a nivel mundial, incidiendo sobre lo económico, lo social, entre otros aspectos. Estos intercambios posibilitan la interacción entre culturas, sirviendo, algunas veces, de gran ayuda. En ese sentido, la "infomulticulturalidad" hace referencia a informaciones provenientes de distintos medios que son asimiladas de una manera diferente y única.

De esta forma, la infomulticulturalidad se basa en el amplio intercambio de información y en la influencia que tiene sobre diferentes culturas que conviven entre sí y que tienen un margen aceptable de tolerancia, elemento primordial para el diálogo intercultural.

6 Se ha concebido la multiculturalidad como una oposición a la tendencia presente, en las sociedades modernas, hacia la unificación y la universalización de cultura, que pretende proteger la variedad cultural, al tiempo que se ocupa sobre las frecuentes relaciones de desigualdad, de las minorías en relación con las culturas mayoritarias. 
No hay duda que la infomulticulturalidad interviene en los procesos de globalización, en el mosaico cultural contemporáneo, en la vorágine informativa y en las nuevas tecnologías de la información y comunicación (figura 1), que implica revisar los alcances de la Internet, el periodismo digital y los recursos multimedia.

Figura 1: elementos de la infomulticulturalidad.

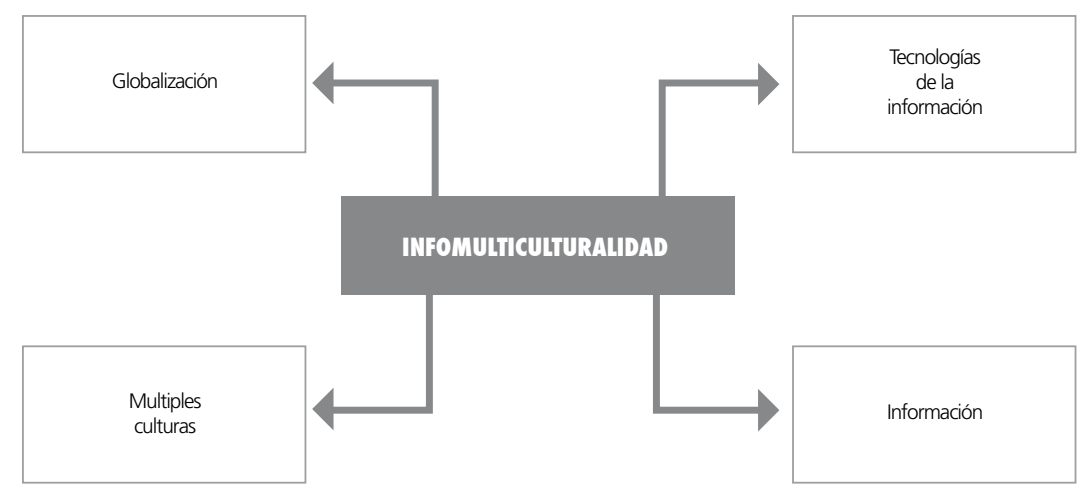

Fuente: Cancino (2012).

\section{Tecnologías de la información}

Son herramientas y recursos empleados para recabar, retener o distribuir información. Generalmente se encuentran asociadas con la informática y nuevos soportes digitales. Estas tecnologías han evolucionado de una manera impresionante, acercando a millones de personas en segundos. La información puede ser obtenida por diversos medios (celulares, computadoras, tabletas electrónicas, entre otros). Asimismo, el auge de las redes sociales ha hecho que la información sea más accesible.

Internet es muchas cosas y sirve a innumerables fines. Hoy es un medio global de comunicación cotidiano en nuestras vidas. De acuerdo con Luis Ángel Fernández (ápud Arjona, 2012), la evolución de la "red de redes" no será nunca previsible; ya que hablamos de una maquinaria forjada por cientos de millones de personas. Si es difícil saber, con antelación, cómo puede evolucionar una ciudad, todo se complica cuando nos referimos a la construcción de la "urbe virtual".

Internet canaliza el material "multimedia", que combina texto, arte gráfico, sonido, animación y video. Este flujo de información, variando en estilo y substancia, fluye por nosotros, en el mundo moderno. Recibimos y procesamos esta información (tanto a niveles conscientes como inconscientes) e incluso ofrece la oportunidad de interactuar con sus contenidos y datos, haciendo que el mensaje sea más efectivo. 
De acuerdo con Riveros (2012), en el transitar de esta revolución tecnológica, uno de los más afectados ha sido el periodismo. En la actualidad, todos tienen el poder de comunicar y su bien más preciado, la información, parece un commodity debido a su abundancia. De esta manera:

"El periodismo ya no es lineal, porque el paradigma emisor-receptor está en franco declive, lo que está provocando una franca revisión en los modelos de negocios de los tradicionales medios de comunicación, donde el carácter bidireccional y multimedia hace que el consumidor de noticias se transforme en un activo prosumidor con mayor poder en la agenda noticiosa, ya que no es un ser pasivo, sino que ahora opina y exige calidad y claridad informativa, o si no crea su propia red en Facebook o Twitter exigiendo poner sus demandas informativas en el mundo simbólico, creando un estado más bien vibracional que sacude en tiempo real la necesidad de información de un vasto grupo de manera instantánea que el típicamente lineal, donde el receptor es quien tiene el poder" (Riveros, 2012).

\section{Reflexiones finales}

La razón de ser de los medios de comunicación social reside en propiciar la racionalidad en el manejo equilibrado y sensato de dichos instrumentos. Esta necesidad de equilibrio se plantea en un momento histórico en el que la introducción de las nuevas tecnologías ha trastocado las funciones de los medios, aumentando el caudal de información y de nuevas realidades.

La denominada "sociedad del conocimiento" exige unos contenidos mediáticos que busquen construir una sociedad mejor. Particularmente, los medios de comunicación social son esenciales para sensibilizar la opinión pública en el proceso de cambio que vivimos; para ayudar a encauzarla y para impulsar los diversos planes de desarrollo, orientándolos según las exigencias del bien común; para divulgar dichos planes y promover la participación activa de toda la sociedad en su ejecución. De esta manera, los medios se convierten en agentes activos del proceso de transformación, cuando se ponen al servicio de una auténtica educación integral, apta para que todo individuo se desarrolle y se perfeccione.

Ante la exposición sistemática de este tipo de mensajes y la incidencia de sus implicancias y consecuencias, el documento "Ética en las Comunicaciones Sociales", editado por el Pontificio Consejo para las Comunicaciones Sociales (2000), considera a la "sociedad de la información" como una verdadera revolución cultural, que plantea nuevas formas de organización y producción de riquezas en la sociedad, donde Internet goza de un papel preponderante en la economía, la política, la educación y en otras dimensiones de la vida.

En esa línea, Benedicto XVI (2008) manifiesta que el papel social de los medios de comunicación "debe considerarse como parte integrante de la cuestión antropológica, que se plantea como un desafío crucial del tercer milenio". Sin embargo, advierte que cuando la comunicación pierde sus raíces éticas y elude el control social, "termina por olvidar la centralidad y la dignidad inviolable del ser humano, y corre el riesgo de incidir negativamente sobre su conciencia y sus opciones, condicionando así la libertad y la vida misma de las personas". 
Por ese motivo, el Papa (2009) recomienda el establecimiento de una "info-ética" que defienda la dignidad humana y así se asegure la comprensión entre las personas y las comunidades, así como la creación de nuevas comunidades y redes, donde se pueda buscar información y noticias, ideas y opiniones de forma libre.

\section{Fuentes consultadas}

- Abarca Fernández, R.

_(2009). “Son los medios de comunicación: constructores de educación?”. Extraída el 4/X/2012 desde http://www.ucsm.edu.pe/rabarcaf/documentos/2012/ MediosComuConstEduc.pdf

_(1998). "El por qué y el para qué de la comunicación”. Ponencia presentada en el 1er. Congreso Internacional de Filosofía y Comunicación. Córdoba, Argentina.

- Almiron, N. (2003). "La aldea del conflicto global”. Extraída el 5/X/2012 desde http:// www.almiron.org/otros $25 . h t m l$

- Arjona, D. (2012, Marzo 20). “¿Para qué querría la gente algo como Internet?” [Entrevista a Luis Ángel Fernández]. Extraída el 5/X/2012 desde http://www.elcultural. es/noticias/LETRAS/2949/Para_que_querria_la_gente_algo_como_Internet

- Barker, A. (2001). Cómo mejorar la comunicación. Introducción a la teoría y a la práctica. Barcelona: Gedisa.

- Benedicto XVI

_(2009, Mayo 24). "Nuevas tecnologías, nuevas relaciones. Promover una cultura de respeto, de diálogo, de amistad. Mensaje para la XLIII Jornada Mundial de las comunicaciones sociales". Extraída el 5/X/2012 desde http://www.vatican. va/holy_father/benedict_xvi/messages/communications/documents/ hf_benxvi_ mes_20090124_43rd-world-communications-day_sp.html

_(2008, Mayo 4). “Los medios: en la encrucijada entre protagonismo y servicio. Buscar la Verdad para compartirla. Mensaje para la XLII Jornada Mundial de las comunicaciones sociales". Extraída el 5/X/2012 desde http://www.vatican.va/holy_father/benedict_ xvi/messages/communications/ documents/hf_benxvi_mes_20080124_42nd-worldcommunications-day_sp.html

- Cancino Velásquez, J. (2012, Marzo 15). "Infomulticulturalidad, comunicación y tecnologías de la información”. Extraída el 5/X/2012 desde http://www.gestiopolis. com/economia-2/infomulticulturalidad-comunicacion-tecnologias-informacion.htm

- Chambers, A. (2002). "Un consejo para escritores principiantes: 'Cuando se trata de escribir, eres lo que lees"”. Extraída el 4/X/2012 desde http://www.imaginaria.com.ar/ 08/0/chambers.htm

- Congregación para la Educación Católica (1986). "Orientaciones sobre la formación de los futuros sacerdotes para el uso de los instrumentos de la comunicación social". 
Extraída el 5/XII/2012 desde http://www.vatican.va/roman_curia/pontifical_councils/ pccs/documents/rc_pc_pccs_doc_19031986_guide-for-future-priests_sp.html

- De León Pérez, H. (2009). "Estudio de la sintaxis de la imagen como método para la alfabetización visual general, según propuesta de Donis A. Dondis". Extraída el 4/X/2012 desde http://biblioteca.usac.edu.gt/tesis/16/16_0646.pdf

- Fernández Collado, C. (1991). La comunicación en las organizaciones. México D. F.: Trillas.

- González, A. (2005, Julio 29). "El compromiso multicultural”. Extraída el 6/X/2012 desde http://arvo.net/cultura-y-humanismo/el-compromiso-multicultural/gmx-niv98con10105.htm

- Habermas, J. (2000). “Aclaraciones a la ética del discurso. Traducción e introducción de Manuel Jiménez Redondo”. Extraída el 5/X/2012 desde http://www.ucm.es/info/ eurotheo/habermas.htm\#1

- Hernández, M. y Mujica, Y. (2008, Noviembre 5). "Proceso de comunicación y sus elementos". Extraída el 4/X/2012 desde http://sorgalim-delaluz.blogspot.com/2008/11/ proceso-de-comunicacin-y-sus-elementos.html

- Juan Pablo II (2005). "El rápido desarrollo. Carta apostólica dirigida a los responsables de las comunicaciones sociales”. Extraída el 5/X/2012 desde http://www.es.catholic.net /comunicadorescatolicos/576/2938/articulo.php?id=21904

- Kovadloff, S. (2008). “¿Hay una lectura real del pasado? La historia como tarea”. Extraída el 4/X/2012 desde http://www.museomitre.gov.ar/conferencia-Kovadloff.htm

- Misioneros del Sagrado Corazón en el Perú (n. d.). "Decreto 'Inter Mirifica' sobre los medios de comunicación social” [Documentos Vaticano II]. Extraída el 5/X/2012 desde http://www.mscperu.org/teologia/vaticanoII/vinter_mirifica.htm

- Pineda de Alcázar, M. (2011). "Las teorías clásicas de la comunicación: balance de sus aportes y limitaciones a la luz del siglo XXI". Revista de Ciencias Humanas y Sociales, núm. 36, pp. 11-29.

- Pontificio Consejo para las Comunicaciones Sociales (2000). "Ética en las comunicaciones sociales". Extraída el 5/X/2012 desde http://www.vatican.va/ roman_curia/pontifical_councils/pccs/documents/rc_pc_pccs_doc_20000530_ethicscommunications_sp.html

- Quinto, J. (2010). "Project to promote Human Development". Extraída el 4/X/2012 desde http://www.aiu.edu/applications/DocumentLibraryManager/upload/TESIS\%20 VERSI\%C3\%93N\%20IMPRESI\%C3\%93N.pdf

- Riveros, E. (2012, Marzo 13). "Periodismo digital y teoría de las cuerdas". El Universal (Caracas). Extraída el 5/X/2012 desde http://www.eluniversal.com/opinion/120313/ periodismo-digital-y-teoria-de-las-cuerdas 
- Rodríguez Bravo, A. (2003). "La Investigación aplicada una nueva perspectiva para los estudios de comunicación”. Cuadernos de Comunicación y Cultura, núm. 30, pp. 17-36.

- Torres, A.; Susin, L. y Sobrino, J. (eds.) (2007). "Teología del pluralismo religioso. El nuevo paradigma”. Revista Internacional de Teología Concilium. Navarra: Verbo Divino. Extraída el 4/X/2012 desde http://www.verbodivino.es/documentos/ PrimerCapituloPDF/2062.pdf

- Tosta Ríos, R. (2011, Mayo 9). “Civilización vs Barbarie: Dr. José María Vargas”. Extraída el 5/X/2012 desde http://www.soberania.org/Articulos/articulo_6340.htm 